\title{
High occurrence of Blastocystis sp. subtypes $1-3$ and Giardia intestinalis assemblage B among patients in Zanzibar, Tanzania
}

\author{
Joakim Forsell ${ }^{1 *}$, Margareta Granlund ${ }^{1}$, Linn Samuelsson'1, Satu Koskiniemi ${ }^{1}$, Helén Edebro ${ }^{1}$ and Birgitta Evengård ${ }^{2}$
}

\begin{abstract}
Background: Blastocystis is a common intestinal parasite with worldwide distribution but the distribution of Blastocystis and its subtypes in East Africa is largely unknown. In this study, we investigate the distribution of Blastocystis subtypes in Zanzibar, Tanzania and report the prevalence of intestinal parasites using both molecular methods and microscopy.

Methods: Stool samples were collected from both diarrhoeic and non-diarrhoeic outpatients in Zanzibar. In addition to microscopy, real-time PCR for Blastocystis, Entamoeba histolytica and E. dispar, Giardia intestinalis, Cryptosporidium spp., and Dientamoeba fragilis was used. Blastocystis subtypes were determined by a conventional PCR followed by partial sequencing of the SSU-rRNA gene. Genetic assemblages of Giardia were determined by PCR with assemblage specific primers.
\end{abstract}

Results: Intestinal parasites were detected in $85 \%$ of the 174 participants, with two or more parasites present in $56 \%$. Blastocystis sp. and Giardia intestinalis were the most common parasites, identified by PCR in 61 and $53 \%$ of the stool samples respectively, but no correlation between carriage of Blastocystis and Giardia was found. The Blastocystis subtype distribution was ST1 $34.0 \%$, ST2 $26.4 \%$, ST3 $25.5 \%$, ST7 $0.9 \%$, and $13.2 \%$ were positive only by qPCR (non-typable). The Giardia genetic assemblages identified were A $6.5 \%$, B $85 \%$, A + B $4.3 \%$, and non-typable $4.3 \%$. The detection rate with microscopy was substantially lower than with PCR, $20 \%$ for Blastocystis and $13.8 \%$ for Giardia. The prevalence of Blastocystis increased significantly with age while Giardia was most prevalent in children two to five years old. No correlation between diarrhoea and the identification of Giardia, Blastocystis, or their respective genetic subtypes could be shown and, as a possible indication of parasite load, the mean cycle threshold values in the GPCR for Giardia were equal in diarrhoeic and non-diarrhoeic patients.

Conclusions: Carriage of intestinal parasites was very common in the studied population in Zanzibar. The most commonly detected parasites, Blastocystis and Giardia, had different age distributions, possibly indicating differences in transmission routes, immunity, and/or other host factors for these two species. In the Blastocystis subtype analysis ST1-3 were common, but ST4, a subtype quite common in Europe, was completely absent, corroborating the geographical differences in subtype distributions previously reported.

Keywords: Zanzibar, Tanzania, Blastocystis, Subtype, Giardia, Assemblage, Real-time PCR, Genotyping

\footnotetext{
*Correspondence: joakim.forsell@umu.se

'Division of Clinical Bacteriology, Department of Clinical Microbiology, Umeå

University, SE-901 87 Umeå, Sweden

Full list of author information is available at the end of the article
} 


\section{Background}

Even though most intestinal parasites are encountered worldwide, they are more common in low-income countries with tropical or subtropical climate and a low grade of sanitation. They are most often spread through faecal-oral transmission routes by ingestion of contaminated food or water. In the last two decades, tools for molecular detection and genetic characterisation of intestinal parasites have been developed, which has improved the ability to diagnose these organisms in stool samples. In addition, genotyping of the parasites has led to several advances, one important example being the separation of morphologically identical Entamoeba cysts into the pathogenic Entamoeba histolytica and the nonpathogenic Entamoeba dispar [1]. An increasing amount of genotype data is being collected for several different species of intestinal parasites which is fundamental to deepen the understanding of pathogenicity, host specificity and transmission patterns of these organisms.

The anaerobic unicellular eukaryote Blastocystis sp. is a unique organism among the intestinal parasites, belonging to the phylum Stramenopiles [2]. It frequently inhabits the gastrointestinal tract of both humans and a large variety of animals [3, 4]. In intestinal parasitological surveys in humans, it is often the most commonly found organism and the prevalence ranges from 7 to $20 \%$ of examined individuals in developed countries [5-7] to 30-60\% [8], or even $100 \%$ [9], in rural areas in developing countries. The presence of Blastocystis in the intestine has been associated with diarrhoea, flatulence, bloating and other irritable bowel syndrome (IBS)-like symptoms. However, the pathogenicity of the organism is debated, mainly because a high carrier-rate has also been reported in asymptomatic individuals. Differences in host susceptibility, host intestinal microbiota and/or different pathogenic potential of the different genetic subtypes of Blastocystis has been put forth as possible explanations to these differences in observed pathogenicity $[10,11]$. There is a high degree of genetic diversity among Blastocystis isolates and the genetic subtypes are named ST1-17 [4, 12-15]. ST1-9 has so far been found in humans, with a majority belonging to ST1-4 [16]. In Africa, the prevalence of Blastocystis subtypes has been studied in the northern and western parts of the continent, namely Egypt [17-20], Libya [16, 21], Senegal [9], Liberia and Nigeria [16], while data from East Africa is sparse. A study from Petrášová et al. [22] described the Blastocystis subtypes found in non-human primates, as well as in six human researchers, in Rubondo Island in the northwest part of Tanzania. Other than that, data on subtype distributions in humans in this region are, to the best of our knowledge, lacking. In this study we have examined the prevalence and subtype distribution of Blastocystis sp. in health care seekers in Jambiani, a coastal village on the island Zanzibar, Tanzania. We have also investigated the general prevalence of intestinal parasites in this population using both microscopy and, for selected parasites, real time PCR.

\section{Methods}

\section{Sample collection and ethical approval}

The presence of intestinal parasites was investigated in people living in Jambiani village, Zanzibar, Tanzania, a small village on the southeast coast of the main island Unguja. The majority of the population is Muslim and engaged in subsistence farming, seaweed farming, fishing and/or tourism. Many of the people live under poor sanitary conditions, with a majority relying on local wells for water supply. For a number of years in the early 2010s clinical stool samples from patients seeking care at an out-patient health clinic in Jambiani, were analyzed for parasites at the Clinical Microbiology laboratory, Umeå, Sweden due to a personal contract between the local health clinic authorities and one of the researchers (BE). Two samples per patient, one stored in L2-buffer containing guanidine thiocyanate [23] and one stored in sodium acetate-acetic acid-formalin fixative (SAF), were sent numbered from anonymised patients for molecular and microscopic parasite detection. In consultation with the medical staff at the health clinic, treatment was given to patients that were diagnosed with what was interpreted as clinically relevant intestinal parasites. All faecal samples were stored at $+4{ }^{\circ} \mathrm{C}$ prior to parasite detection and DNA used for molecular detection was kept frozen at $-70{ }^{\circ} \mathrm{C}$. In this study, consecutively collected samples were further examined with subtyping of Blastocystis sp. and Giardia intestinalis. The study was approved by the regional ethical board at Umeå University, Sweden (Dnr 2012-406-31M). The samples investigated could be divided into two groups, one from patients zero to ten years old irrespective of the presence of diarrhoea $(n=108)$ and patients more than ten years old mainly with diarrhoea $(62 / 66)$.

\section{Microscopy}

Samples stored in SAF were concentrated by the formolether-concentration technique (FECT) [24] followed by parasite detection by light microscopy. Iodine staining was used to detect helminth ova and protozoan cysts, and a modified Ziehl-Neelsen acid-fast staining, using carbol fuchsin, decolorization with hydrochloric acid and counterstaining with malachite green, was used to detect coccidian oocysts of genera Cryptosporidium, Cyclospora and Cystoisospora.

\section{DNA extraction}

DNA was extracted from samples stored in L2 buffer (guanidine-thiocyanate $0.96 \mathrm{~g} / \mathrm{ml}$ dissolved in $0.1 \mathrm{M}$ 
Tris, $\mathrm{pH}$ 6.4) using a method previously developed in our laboratory [23]. Briefly, 150-200 mg faeces was collected with a flocked nylon swab (ESwab, Copan) and transferred to $1 \mathrm{ml}$ of Amies medium, $400 \mu \mathrm{l}$ of this suspension was transferred to a tube with Lysing matrix $\mathrm{E}$ that contains beads (MP Biomedicals, Nordic Biolabs AB, Täby, Sweden). Bead beating was performed with a FastPrep-24 Instrument at $6 \mathrm{~m} / \mathrm{s}$ for $40 \mathrm{~s}$ (MP Biomedicals). Following centrifugation, $250 \mu \mathrm{l}$ lysate was diluted with $250 \mu \mathrm{l}$ nuclease free (NF)-water and transferred to the automatic instrument Arrow and run with Arrow stool DNA kit according to the manufacturer's instructions (NordDiag, Oslo, Norway). DNA was eluted in $100 \mu$ l elution buffer and stored in $-70{ }^{\circ} \mathrm{C}$ before PCR amplification.

\section{Real-time PCR (qPCR) assays to detect Entamoeba histolytica, Entamoeba dispar, Giardia intestinalis, Cryptosporidium spp. and Dientamoeba fragilis}

Entamoeba histolytica and Entamoeba dispar were detected by a previously described duplex qPCR assay with the genus specific primer pair Ehd-239 F and Ehd-88R and the species specific probes Histolytica $96 \mathrm{~T}$ and Dispar $96 \mathrm{~T}$ [25]. The reaction mixture contained $12.5 \mu \mathrm{l}$ TaqMan Universal PCR Master Mix (Applied Biosystems, Life Technologies, Stockholm, Sweden), primers Ehd-239 F (5' -ATT GTC GTG GCA TCC TAA CTC A$\left.3^{\prime}\right)$ and Ehd-88R (5' -GCG GAC GGC TCA TTA TAA CA-3') each at $176 \mathrm{nM}$, probes histolytica $96 \mathrm{~T}$ (VIC 5'-TCA TTG AAT GAA TTG GCC ATT T-3'MGBNFQ) and dispar 96 T (FAM 5' -TTA CTT ACA TAA ATT GGC CAC TTT G-3'-MGBNFQ) each at $224 \mathrm{nM}$, $5 \mu \mathrm{l}$ DNA template, and nuclease free (NF)-water to a final volume of $25 \mu \mathrm{l}$. A multiplex qPCR assay developed at the Dutch National Institute for Public Health and the Environment (RIVM) using previously published primers and probes was used to detect Giardia intestinalis [26], Dientamoeba fragilis [27] and Cryptosporidium spp. [28]. The assay was modified from a Lightcycler protocol to a Taqman protocol with different fluorophores and quenchers conjugated to the probes. Our reaction mixture consisted of $12.5 \mu \mathrm{l}$ TaqMan Universal PCR Master Mix (Applied Biosystems), primers Giardia 80 F (5'-GAC GGC TCA GGA CAA CGG TT-3') and Giardia 127R (5'TTG CCA GCG GTG TCC G-3') each at $200 \mathrm{nM}$, probe Giardia T (FAM-5'-CCC GCG GCG GTC CCT GCT AG-3' BHQ1) at $40 \mathrm{nM}$, primers $\mathrm{CrF}\left(5^{\prime}-\mathrm{CGC}\right.$ TTC TCT AGC C TT TCA TGA-3') and CrR (5' ${ }^{\prime}$-CTT CAC GTG TGT TTG CCA AT-3') each at $600 \mathrm{nM}$, probe Crypto (CY5-5'-C CA ATC ACA GAA TCA TCA GAA TCG ACT GGT ATC$3^{\prime}$-BHQ2) at $200 \mathrm{nM}$, primers Df-124 F (5'-CAA C GG ATG TCT TGG CTC TTT A-3') and Df-221R (5' ${ }^{\prime}$ TG C ATT CAA AGA TCG AAC TTA TCA C-3') each at 560 nM, probe Df-172revT (VIC-5' ${ }^{\prime}$ CAA TTC TAG CCG CT
T AT-3'-BHQ1) at $200 \mathrm{nM}, 0.5 \mu \mathrm{l} \mathrm{BSA} 8 \mathrm{mg} / \mathrm{ml}, 5 \mu \mathrm{l}$ DNA template and NF-water to a final volume of $25 \mu$ l. The amplification for both assays were similar, and consisted of $50{ }^{\circ} \mathrm{C}$ for $2 \mathrm{~min}, 95^{\circ} \mathrm{C}$ for $10 \mathrm{~min}$ followed by 45 cycles of denaturation at $95{ }^{\circ} \mathrm{C}$ for $15 \mathrm{~s}$ and annealing and extension at $58{ }^{\circ} \mathrm{C}$ for $1 \mathrm{~min}$ in the Entamoeba-assay and at $60{ }^{\circ} \mathrm{C}$ for $1 \mathrm{~min}$ in the Giardia-Cryptosporidium-Dientamoeba-assay. All DNA templates were analysed undiluted and diluted 1/ 10 on a 7500 fast real-time PCR system (Applied Biosystems).

\section{Blastocystis barcoding}

Blastocystis was initially detected and subtyped by the Blastocystis barcoding method previously described, using primers RD5 (5' -ATC TGG TTG ATC CTG CCA GT-3') and BhRDr (5' -GAG CTT TTT AAC TGC AAC AAC G$3^{\prime}$ ) [29]. One $\mu \mathrm{l}$ DNA was used in a reaction mixture of $20 \mu$ Biomix (Bioline, London, UK), each primer at 250 $\mathrm{nM}$, and NF-water to a total volume of $40 \mu \mathrm{l}$. Amplification included an initial step at $94{ }^{\circ} \mathrm{C}$ for $5 \mathrm{~min}$ followed by 30 cycles of denaturation, annealing and extension at $94{ }^{\circ} \mathrm{C}, 59$ and $72{ }^{\circ} \mathrm{C}$ ( 1 min each) and was completed by a final extension at $72{ }^{\circ} \mathrm{C}$ for $2 \mathrm{~min}$. All negative samples were run an additional time with the DNA diluted $1 / 10$ before considered negative. Positive PCR products were purified using illustra MicroSpin S-300 HR columns (GE Healthcare, Little Chalfont, UK). Purified PCR products were sequenced using the primer BhRDr, ABI BigDye terminator kit version 1.1 and an ABI 3130xl Genetic Analyzer (Applied Biosystems). Sequencing chromatograms were analysed in the software Chromas Lite version 2.1.1 (Technelysium, Brisbane, Australia). Subtypes were identified by BLAST searches at the National Center for Biotechnology Information (NCBI) determining the exact match or closest similarity to Blastocystis sequences previously deposited in GenBank. The nomenclature for subtypes presented by Stensvold et al. [12] was used.

\section{qPCR assay to detect Blastocystis sp.}

To increase the sensitivity of Blastocystis detection, all samples negative by the initial barcoding PCR were analysed with a qPCR assay described by Stensvold et al. [30] using primers Blasto FWD F5 (5'-GGT CCG GTG AAC ACT TTG GAT TT-3') and Blasto R F2 (5'CCT ACG GAA ACC TTG TTA CGA CTT CA-3') with the Blastocystis probe FAM-5' -TCG TGT AAA TCT TAC CAT TTA GAG GA-3'-MGBNFQ). The reaction mixture consisted of $5 \mu \mathrm{l}$ DNA template, $12.5 \mu \mathrm{l}$ TaqMan Universal PCR Master Mix (Applied Biosystems), each primer at $900 \mathrm{nM}$, hydrolysis probe at $110 \mathrm{nM}$, and NF-water to a final volume of $25 \mu \mathrm{l}$. DNA templates were analysed in dilutions $1 / 10$ and $1 / 50$. The amplification 
consisted of $50{ }^{\circ} \mathrm{C}$ for $2 \mathrm{~min}, 95{ }^{\circ} \mathrm{C}$ for $10 \mathrm{~min}$ followed by 45 cycles of $95^{\circ} \mathrm{C}$ for $15 \mathrm{~s}$ and $60^{\circ} \mathrm{C}$ for $1 \mathrm{~min}$.

\section{Giardia assemblage typing}

Giardia identified by qPCR were assigned to genetic assemblages by conventional PCR, assay 4E1-HP developed by Vanni et al. [31], with specific primers for assemblage A (forward 5'-AAA GAG ATA GTT CGC GAT GTC-3', reverse 5' -ATT AAC AAA CAG GGA GAC GTA TG-3') and assemblage B (forward 5'GAA GTC ATC TCT GGG GCA AG-3', reverse 5'GAA GTC TAG ATA AAC GTG TCG G-3'). Originally presented as a duplex assay we used the primer pairs in two separate reactions, which in our hands was more sensitive for mixed infections. An increase in primer concentration from $200 \mathrm{nM}$ to $400 \mathrm{nM}$ yielded easier to read PCR products. Both reaction mixtures contained $2 \mu \mathrm{l}$ of DNA, $25 \mu \mathrm{l}$ of BioMix (Bioline), each of the respective primers at $400 \mathrm{nM}$, and NF-water to a final volume of $50 \mu \mathrm{l}$. Amplification was performed on a conventional thermocycler (MyCycler, BioRad Laboratories, Solna, Sweden) with an initial step of $94{ }^{\circ} \mathrm{C}$ for 5 min followed by 40 cycles of 94,56 and $72{ }^{\circ} \mathrm{C}$ for $30 \mathrm{~s}$ each, completed by a final extension at $72{ }^{\circ} \mathrm{C}$ for $7 \mathrm{~min}$. Amplification products were visualized on $1.5 \%$ agarose gels stained with ethidium bromide. Negative samples were analysed with DNA diluted $1 / 10$ to decrease the influence of inhibitors. Remaining negative samples were further examined using NanoDrop (Fisher Scientific, Sweden) for DNA concentration and protein-DNA ratio. A majority of these samples was shown to have a low DNA concentration and were then run with a higher quantity of DNA, $5 \mu \mathrm{l}$.

\section{PCR inhibition control}

For control of PCR inhibitors we used a linearized plasmid with a 720 bp insert of Drosophila melanogaster ALKcDNA (Christina Lorén, Umeå Center for Molecular Pathogenesis, Umeå, Sweden) in the vector pcDNA3 (Invitrogen, Life Technologies Europe, Stockholm, Sweden). This internal positive control (IPC) was added to all undiluted and diluted 1/10 DNA templates with 125 copies per reaction and was detected by a previously described qPCR assay [23]. The expected cycle threshold $(\mathrm{Ct})$ value was 29,3 and $\mathrm{Ct}$ values above 32.5 were considered as signs of relative inhibition [23].

\section{Statistical analysis}

Statistical analysis was performed using the software PASW version 18 (SPSS Inc, Chicago, IL, USA). Pearsons $X^{2}$ test was used for group comparisons of proportions of samples that were positive or negative by microscopy or PCR assays. qPCR Ct values, with higher values indicating lower amounts of target DNA, were compared with independent sample $t$-test.

\section{Results}

Patients and samples

Stool samples from 174 patients visiting the Jambiani Health Clinic were examined. Among the children less than ten years of age 55/108 (50.9 \%) had diarrhoea. Sampling of participants aged $\geq$ ten years was mainly performed on patients with diarrhoea $(62 / 66)$ but also included a few patients without diarrhoea (4/66). Nondiarrhoeic patients had other health problems, most commonly respiratory symptoms or fever. The participants were subdivided into age groups (with the number of individuals in each group in parenthesis): $0<2$ (35), 2 $<6$ (35), $6<10$ (38), $10<15$ (36), and $15-71$ years of age (30). In total, 94 were male $(54 \%)$ and 80 (46\%) were female.

\section{Intestinal parasites identified by PCR-based methods and microscopy after FECT}

Summarizing all methods used, intestinal parasites were detected in $85.1 \%$ of the 174 patients (Table 1 ). Infection with more than one parasite was a common finding. Two, three, four and five parasites were detected in 29.3, $22.4,2.9$ and $1.1 \%$ of the patients, respectively. A single organism was found in only $29.3 \%$ of the patient samples. Using PCR-based methods Blastocystis sp. and Giardia intestinalis were the most prevalent species, found in $60.9 \%(106 / 174)$ and $53.4 \%(93 / 174)$ of the patients, respectively, followed by Dientamoeba fragilis in $16.7 \%$ (29/174) (Fig. 1). Entamoeba dispar and Entamoeba histolytica were found in few samples (Table 1). Cryptosporidium spp. was only detected in two patients, both of whom were less than two years old. In 20 samples the initial PCR reaction for the internal control IPC was inhibited but no inhibition was noted after $1 / 10$ dilution of extracted DNA.

Table 1 Intestinal parasites detected in patients in Zanzibar

\begin{tabular}{lll}
\hline & PCR & Microscopy \\
& (\% positive patients) & (\% positive patients) \\
\hline Blastocystis sp. & 60.9 & 20.1 \\
Giardia intestinalis & 53.4 & 13.8 \\
Entamoeba coli & na & 21.3 \\
Dientamoeba fragilis & 16.7 & na \\
Trichuris trichiura & na & 6.9 \\
Entamoeba dispar & 5.7 & $1.7^{\mathrm{a}}$ \\
Endolimax nana & na & 2.9 \\
Cryptosporidium spp. & 1.1 & 0.6 \\
Chilomastix mesnili & na & 1.1 \\
Ascaris lumbricoides & na & 0.6 \\
Entamoeba histolytica & 0.6 & 0 \\
\hline
\end{tabular}

Abbreviation: na, the method was not used for detection

${ }^{a}$ Entamoeba histolytica and E. dispar can not be separated by microscopy but subsequent PCR identified E. dispar 


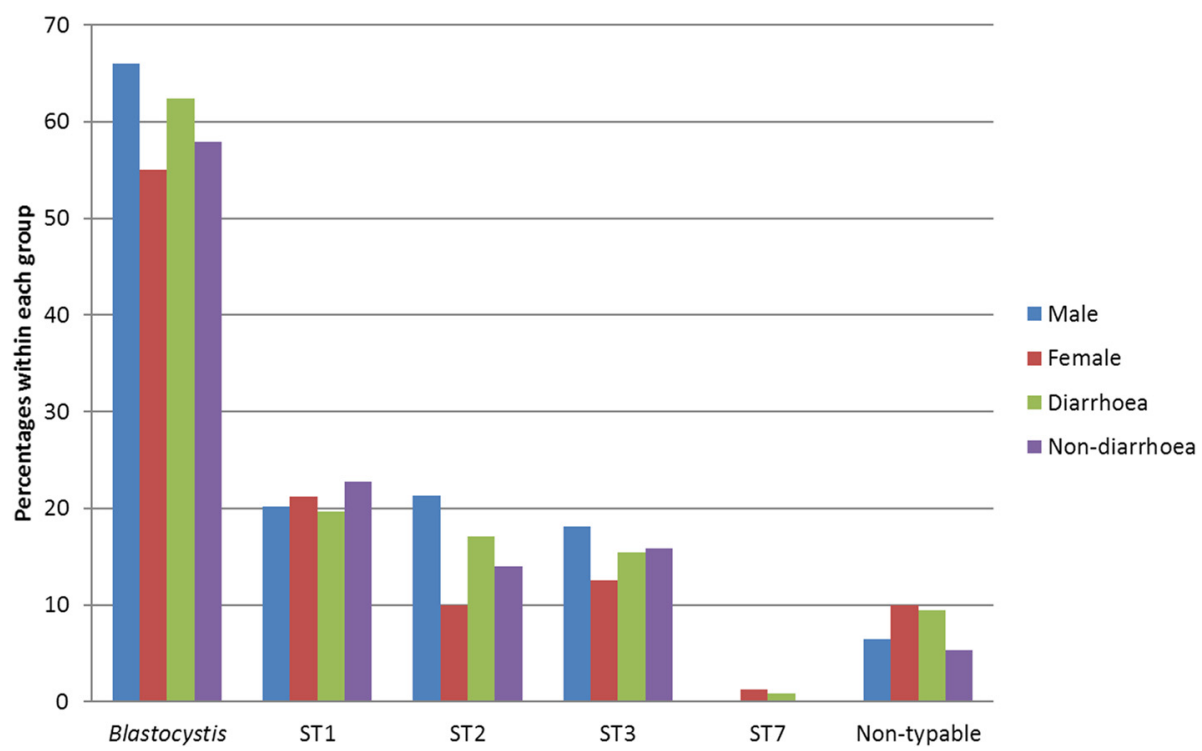

Fig. 1 Prevalence of Blastocystis sp. and genetic subtypes in males and females and in cases with and without diarrhoea

By microscopy of faecal samples after FECT Entamoeba coli was the most common finding, present in $21.3 \%$ of the samples, followed by Blastocystis sp. and Giardia intestinalis in 20.1 and $13.8 \%$, respectively. The presence of helminths in the stool samples was only investigated by microscopy, no PCR-based methods were used. Trichuris trichiura was the most common helminthic species with a prevalence of $6.9 \%$. Ascaris lumbricoides was only found in one patient (Table 1).

In all species for which both methods were used PCR was more sensitive than identification with microscopy. Six cases of Blastocystis sp. detected by microscopy were negative by the initial barcoding PCR assay. Subsequent qPCR for Blastocystis was positive in four out of these six cases (with $\mathrm{Ct}$ values between 25.6 and 33.1). Overall, the conventional PCR used for Blastocystis was more than twice as sensitive as the identification with microscopy - and combined with the qPCR results the molecular tests - detected three times as many Blastocystis as microscopy. All G. intestinalis, E. histolytica/dispar and Cryptosporidium spp. identified by microscopy were also positive by $\mathrm{qPCR}$. The sensitivity to detect $G$. intestinalis by qPCR was more than three times greater than that of microscopy. As a reflection of a possible difference in the number of parasites present in the samples the $\mathrm{Ct}$ values in the GPCR were substantially lower (mean 20.8, interquartile range 17.8-24.1) in the samples positive for Giardia in microscopy than in microscopy negative samples (mean 30.8, interquartile range 25.2-36.3; $t_{(56)}=8.316$, $P<0.001)$. The one case of $E$. histolytica detected by qPCR (Ct value 35.0 ) was not detected by microscopy.

When seeking correlations between the most commonly detected parasites, we found that Blastocystis was present in 31 of 37 samples where Entamoeba coli was detected $\left(\chi^{2}=10.32, d f=1, P=0.001\right)$ and in 23 of 29 Dientamoeba positive samples $\left(\chi^{2}=4.94, d f=1, P=0.026\right)$. We observed no significant correlation between Blastocystis and Giardia carriage $\left(\chi^{2}=1.09, d f=1, P=0.297\right)$.

\section{Blastocystis sp. subtyping}

The barcoding PCR for Blastocystis sp. was positive in 85 cases ( $48.9 \%$ of the patients) and all these Blastocystis were successfully subtyped. By analysing Blastocystis negative samples with $\mathrm{qPCR}$ an additional 21 cases were found, to a total of 106 positive individuals (60.9\%). Optimised attempts at subtyping the qPCR positive cases were successful in seven out of these 21. In total, the identified subtypes were: ST1 36 (34.0 \%), ST2 28 (26.4\%), ST3 27 (25.5\%), ST7 1 (0.9\%), and non-typable 14 (13.2\%). The qPCR amplifies around $c .115$ bp of the SSU-RNA gene. The small size of the product contributes to the high sensitivity of the qPCR but leads to a low ability to discriminate between the Blastocystis subtypes. No double peaks in the sequencing chromatograms that would indicate mixed infections with more than one subtype were found with the set of analyses we used. In Table 2 the subtype distribution in this study is presented together with the distributions found in other African countries according to the literature. We found no statistically significant difference in carrier-rates of Blastocystis between males (66.0 \%) and females (55.0\%). An observed difference in prevalence for ST2 in males $(21.3 \%)$ compared to females $(10 \%)$ did not reach statistical significance, $\left(\chi^{2}=2.62, d f=1, P=0.105\right)$ (Fig. 1). 
Table 2 Blastocystis sp. subtype distribution in different African countries. Subtypes assigned by sequence-tagged site primers or partial sequencing of the SSU-rRNA gene

\begin{tabular}{|c|c|c|c|c|c|c|c|c|c|c|c|c|}
\hline \multirow[t]{2}{*}{ Country [reference] } & \multirow[t]{2}{*}{ Subtyping method } & \multirow[t]{2}{*}{ No. of observations } & \multicolumn{10}{|c|}{ Subtype ${ }^{a}$} \\
\hline & & & 1 & 2 & 3 & 4 & 5 & 6 & 7 & 8 & 9 & Mixed \\
\hline Egypt [17] & $\mathrm{STS}^{\mathrm{C}}$ & 44 & 8 & - & 24 & - & - & 8 & 4 & - & - & - \\
\hline Egypt [18] & Sequencing & 21 & 4 & 4 & 13 & - & - & - & - & - & - & $1^{d}$ \\
\hline Egypt [19] & STS ${ }^{c}$ & 110 & 15 & - & 49 & - & - & 33 & 13 & - & - & $10^{\mathrm{d}}$ \\
\hline Egypt [20] & $\mathrm{STS}^{\mathrm{C}}$ & 36 & 6 & - & 30 & - & - & - & - & - & - & - \\
\hline Liberia [16] & Sequencing & 25 & 7 & 7 & 8 & 3 & - & - & - & - & - & $5^{e}$ \\
\hline Libya [16] & Sequencing & 38 & 19 & 3 & 15 & - & - & - & 1 & - & - & - \\
\hline Libya [21] & Sequencing & 48 & 26 & 13 & 9 & - & - & - & - & - & - & $3^{d}$ \\
\hline Nigeria [16] & Sequencing & 22 & 10 & - & 9 & 3 & - & - & - & - & - & $1^{\mathrm{e}}$ \\
\hline Senegal [9] & Sequencing & 93 & 29 & 21 & 51 & 2 & - & - & - & - & - & $8^{d}$ \\
\hline Tanzania [22] & Sequencing & 6 & 1 & 3 & 2 & - & - & - & - & - & - & - \\
\hline Tanzania $^{\mathrm{b}}$ & Sequencing & 92 & 36 & 28 & 27 & - & - & - & 1 & - & - & - \\
\hline Total & & 535 & 161 & 79 & 237 & 8 & - & 41 & 19 & - & - & 28 \\
\hline
\end{tabular}

a Subtypes denoted according to a consensus denomination [12]

${ }^{\mathrm{b}}$ Present study

'STS = sequence-tagged site primers (specific for each subtype 1-7)

${ }^{\mathrm{d}}$ Subtypes involved in mixed infections were resolved and were added to the distribution

eSubtypes involved in mixed infections were not resolved

\section{Giardia intestinalis assemblage typing}

The 93 G. intestinalis identified by qPCR were assigned to genetic assemblages by conventional PCR. A single infection with G. intestinalis assemblage B was found in 79 of these 93 samples (85\%), a single infection with assemblage A in six cases (6.5\%), and mixed infections of assemblages A and B in four cases (4.3\%). In four samples $(4.3 \%)$ neither of the two tested assemblages were identified despite rigorous attempts at optimising the PCR, these samples were also negative by microscopy and the $\mathrm{Ct}$ values in the Giardia-qPCR were 33.8-36.2, indicating relatively low amounts of target DNA. No significant difference in the presence of either G. intestinalis or Giardia assemblage B was noted when males (56.4 and $48.9 \%$ respectively) and females (50.0 and $41.2 \%$ respectively) were compared (Fig. 2). The number of assemblage A cases were too low for valid comparisons.

\section{Presence of intestinal parasites in relation to age}

The prevalence of Blastocystis sp., G. intestinalis and D. fragilis in different age groups is presented in Fig. 3. Detection of Giardia was associated with younger age and was more often identified among the youngest individuals compared to those ten years of age or older. The highest prevalence of Giardia was seen among children aged two to five years, with a carrier-rate of $74.3 \%$, which decreased to $46.7 \%$ in the age group 15 years or older (Fig. 3). The presence of Blastocystis gradually increased with age. A highly significant difference was seen between both the two youngest age groups where Blastocystis was detected in 25.7 and $51.4 \%$ respectively and in teenagers and adults in which around $80 \%$ of the individuals carried Blastocystis in their intestine $\left(\chi^{2}=24.57, d f=1, P<0.001\right)$ (Fig. 3). The older age groups preferentially consisted of patients with diarrhoea which may have distorted the results. However, the same relationship to age was seen when only diarrhoeic cases were compared since no correlation between either Blastocystis sp. or G. intestinalis and the presence or absence of diarrhoea was found in any age group (see below).

\section{Diarrhoea among patients in relation to identified parasites in stool samples}

By comparing carrier-rates in cases with and without diarrhoea we found no statistically significant correlation between diarrhoea and the presence of intestinal parasites or the number of parasites infecting each individual. Furthermore, there were no significant differences in carrier-rates in cases with diarrhoea and without diarrhoea for Blastocystis sp. (62.4 vs 57.9 \%); Blastocystis subtypes ST1 (19.7 vs 22.8 \%), ST2 (17.1 vs $14.0 \%$ ), ST3 (15.4 vs 15.8 \%) (Fig. 1); G. intestinalis (49.6 vs 61.4 \%); Giardia assemblage B (41.9 vs $52.6 \%$ ) (Fig. 2); D. fragilis (14.5 vs $21.1 \%$ ); or E. coli (20.5 vs $22.8 \%$ ). This held true not only for the whole study population but also for each age group and gender separately analysed (data not shown). The detected numbers of the other parasite species, including Giardia assemblage A, were too low for valid comparisons of symptomatology. No difference in $\mathrm{Ct}$ values was noted in the qPCR for Giardia when stool samples from patients with or without diarrhoea were compared (mean Ct values 28.2 and 28.5, respectively). 


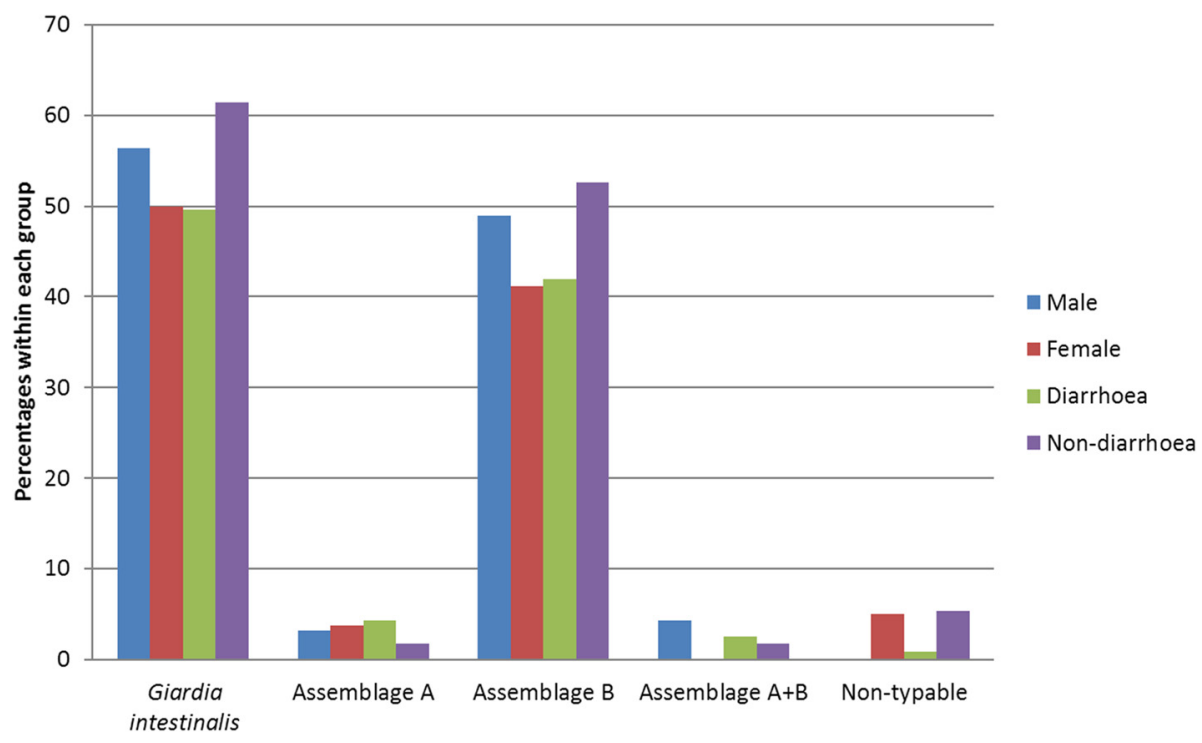

Fig. 2 Prevalence of Giardia intestinalis and genetic assemblages in males and females and in cases with and without diarrhoea

\section{Discussion}

In this study we investigated the occurrence of parasites and the genetic diversity of intestinal protozoa in the stools of individuals seeking community health care in a village in Zanzibar, Tanzania.

\section{Prevalence of intestinal parasites using microscopy and PCR-based methods}

We found a high prevalence of parasites in the stool samples of the 174 participants, $85.1 \%$ harboured one or more parasites. The high prevalence compared to many other studies can possibly be related to the significantly higher detection rate observed by PCR compared to microscopy. The two most commonly found parasites, Blastocystis sp. and G. intestinalis were detected three times more often by qPCR than by microscopy. An increased sensitivity of molecular detection methods has also been shown by others [32-34]. The detection rate with microscopy would probably have increased if we had collected three samples instead of one. The sensitivity of investigating one individual stool sample by FECT and microscopy, compared to an examination of three

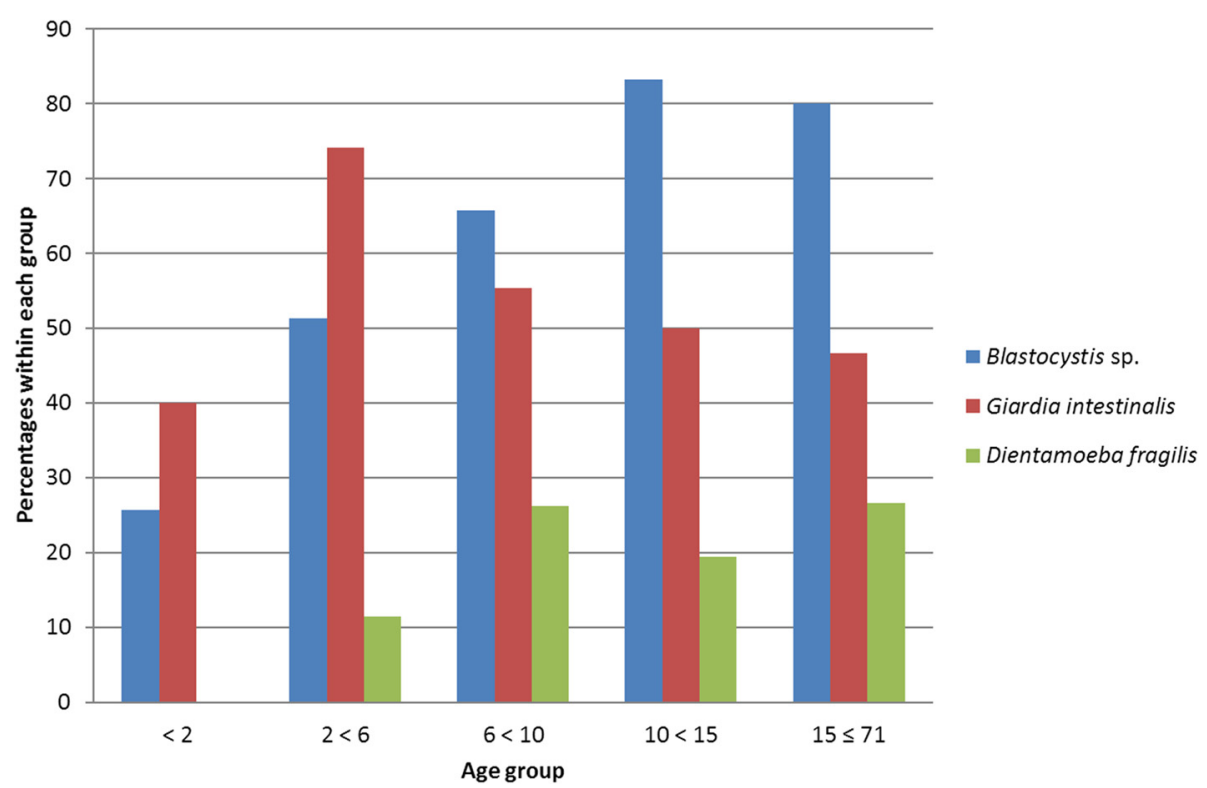

Fig. 3 Presence of Blastocystis sp., Giardia intestinalis and Dientamoeba fragilis in stool samples from patients in different age groups in Zanzibar 
stool samples, has been shown to be around $75 \%$ for intestinal parasites in general [35] and G. intestinalis in particular [36]. Taking that into account qPCR would still be vastly more sensitive. The higher qPCR Ct values for Giardia found in samples not detected by microscopy may indicate that the increased detection rate in large is due to detection of low pathogen loads in the sample. Only one case of Entamoeba histolytica was found by qPCR. In this sample, no cysts of E. histolytica/ dispar were found by microscopy and the $\mathrm{Ct}$ value in the qPCR assay was 35.0, indicating that a low number of parasites may have been present in the sample. This discrepancy in detection rates between PCR-based methods and microscopy combined with the relative quantification derived from qPCR-assays could be of interest for further studies of the association between gastro-intestinal symptoms and the presence of unicellular eukaryotes in the intestine.

In a previous study from northwest Zanzibar investigating gastro-intestinal pathogens in children aged two to 59 months, including Cryptosporidium as the only parasite, Cryptosporidia were a common finding [37]. This is in contrast to the rare occurrence of Cryptosporidium in our study, with only two detected cases. The difference may relate to local geographic differences, the occurrence of a local outbreak, selection of study participants (fever and diarrhoea were inclusion criteria for the symptomatic group in their study), or seasonality of the infections. Similarly, few cases of helminth infections were detected in our study. Infections with the soiltransmitted helminths Ascaris lumbricoides, Trichuris trichiura and hookworms are globally among the most common human infections and was also described as a major public health problem in Zanzibar in the early 1990s [38]. However, in 1994 a National Helminth Control Programme was initiated in school-aged children in Zanzibar [39] which may explain the few helminth infections detected.

\section{Prevalence and subtype distribution of Blastocystis sp.}

Blastocystis was the most prevalent parasite in this study, found in $60.9 \%$ of the study participants, with a similar prevalence in patients with and without diarrhoea (Fig. 1).

Another study from sub-Saharan Africa by El Safadi et al. [9], detecting Blastocystis in children in Senegal by using the barcoding method [29] and a GPCR assay developed by Poirier et al. [40], found a Blastocystis prevalence of $100 \%$ in the studied population of both symptomatic and asymptomatic children aged six to ten years old. Conflicting results regarding the incidence of Blastocystis in different age groups can be found in the literature [41-43]. This can in part be explained by study design, where only children or only adults have been examined, or when relatively few Blastocystis have been detected by conventional techniques. In a large study from Brazil Cabrine-Santos et al. [42] showed that the prevalence of Blastocystis in children was significantly higher above the age of six. This is in agreement with our findings where the prevalence of Blastocystis was significantly lower in children below the age of six than in children older than ten years and adults, in which around $80 \%$ of the patients carried Blastocystis (Fig. 3). However, our results from individuals over ten years old should be substantiated by a larger study because of a small number of non-diarrhoeic controls $(6.1 \%)$ and the wide age spread among the 30 individuals that constitute the oldest age group 15-71 years of age.

In the subtype analysis, ST1 was the most commonly found subtype, followed by ST2 and ST3, with a rather even distribution between these three subtypes. No mixed infections were detected. A higher prevalence of mixed infections may be possible to identify with other methods, as has been suggested in a recent study in which a high percentage of mixed infections, especially involving ST1, was found in stool samples from healthy humans with the use of a ST-specific nested PCR [44]. Globally, ST3 is the most commonly detected subtype followed by ST1 [16]. This pattern is also seen in the compiled studies from Africa, shown in Table 2. A predominance of ST1 has been reported in some studies from Africa [16, 21], Asia [45, 46] and South America [47]. ST1 was also found among non-human primates in the northwest region of Tanzania [22]. ST4, which is common in Europe accounting for $24.2 \%$ of studied Blastocystis isolates [16, 48], was completely absent in our study. Low prevalence or complete absence of ST4 has repeatedly been found in studies from Asia and Africa [16]. How the different Blastocystis subtypes are spread and why ST4 is absent in certain areas of the world is not known. The authors of a study on Blastocystis subtype prevalence in the UK, Liberia, Libya and Nigeria [16] point out that ST4 seems rare in regions where ST1 is the dominant subtype and in regions with mainly Muslim populations, both of which are true for our study. These geographical differences in Blastocystis subtype prevalence prompts the need to investigate the molecular epidemiology of Blastocystis in regions and populations not previously investigated.

Our findings, with a high prevalence of Blastocystis, an increasing prevalence with age, and the absence of mixed subtype infections, might indicate a gradual establishment of Blastocystis carriage over time. Further longitudinal studies on the length and stability of Blastocystis subtype carriership are needed to determine if the high prevalence in older children and adults is caused by frequent reinfections or, once acquired, stable long term colonisation, and if so, its role in the human intestinal microbiota. We 
found no correlation between diarrhoea and any specific Blastocystis subtype. Research on the pathogenic potential of different subtypes is ongoing and some studies have indicated certain subtypes as more likely to be pathogenic (reviewed in Roberts et al. [10]), but to date, no clear distinction between pathogenic and nonpathogenic subtypes have been made.

\section{Prevalence and assemblage distribution of Giardia intestinalis}

Giardia intestinalis is a common cause of diarrhoea worldwide, with approximately 280 million cases of giardiasis annually [49]. The highest prevalence of giardiasis is seen in tropical and subtropical low-income countries. Giardia is considered a significant cause of diarrhoea and nutritional disorders in these countries and is included in the WHO Neglected Diseases Initiative with the aim to improve health and socio-economic development [50]. In endemic areas, Giardia is especially prevalent among children and asymptomatic infections are common [51-53]. In our study the presence of Giardia was high in all age groups investigated but was most prevalent in children two to five years of age, where the parasite was detected in as many as $74 \%$.

Isoenzyme electrophoresis investigations on Giardia isolates have found seven genetic subgroups, named assemblage A to $G$, where A and B predominately infect humans [54]. Molecular characterisation has shown that the genomes of assemblage A and B share $77 \%$ identity in protein coding regions, which suggest that they may represent two separate species [55]. The high detection rate of Giardia found by $\mathrm{QPCR}$ in our study was confirmed by the conventional PCR assays for $G$. intestinalis assemblage $\mathrm{A}$ and $\mathrm{B}$ that gave positive results for 89 of 94 qPCR positive cases, $85 \%$ of which were assemblage B. The lack of assemblage identification in four samples positive in qPCR for Giardia may indicate that these Giardia belong to another assemblage. However, the samples were negative by microscopy and had high $\mathrm{Ct}$ values in the $\mathrm{qPCR}$ and we think that a more plausible explanation is a low number of organisms present in these samples. The prevalence of G. intestinalis found in our study, $53.4 \%$ by qPCR and $13.8 \%$ by microscopy, and a dominance of assemblage $\mathrm{B}$, is similar to findings in a study of intestinal parasites among children under five years of age in Rwanda [56], where the authors found G. intestinalis by qPCR in $59.7 \%$, by microscopy in $19.8 \%$ and assemblage B in $86 \%$ of the Giardia positive cases. A predominance of assemblage $B$ has also been found in Pemba Island, Zanzibar, Tanzania [57], as well as in studies from other African countries such as Guinea-Bissau [58], Morocco [59], Algeria [60], Uganda [53], Côte d'Ivoire [61] and Egypt [62-64]. Assemblage A was the most prevalent genotype in another study from Egypt [65] and in one study from Ethiopia [66]. Studies regarding the association of assemblage A and B to symptomatic infections have reached discordant conclusions [67]. Our data included too few cases of assemblage A infections to reliably investigate any differences in pathogenic potential between the assemblages. Larger studies are needed to determine if the non-dominant assemblage in Giardia endemic regions has a different virulence to the dominant assemblage.

\section{The role of Blastocystis sp. and Giardia intestinalis in causing diarrhoea}

Both Blastocystis and Giardia were common findings, among both diarrhoeic and non-diarrhoeic individuals. This is an interesting background to the debate regarding the pathogenicity of Blastocystis and the role intestinal parasites have in causing gastro-intestinal symptoms. In a case-control study on diarrhoea among children under five years in Tanzania $52.2 \%$ of asymptomatic individuals carried one or more enteropathogens. The authors found that Shigella was the only detected organism statistically linked to diarrhoea - Salmonella, ETEC, EPEC, EAEC and Giardia were not [68]. Similarly, Platts-Mills et al. found an association between diarrhoea and detection of Shigella/enteroinvasive Escherichia coli, rotavirus and astrovirus in Tanzanian infants; however, only when the quantity of the organisms was taken in consideration [69]. In our study, Ct values used as a measure of abundance were indistinguishable between patients carrying Giardia with or without diarrhoea. In western countries patients are treated both in symptomatic and asymptomatic Giardia cases, the latter to prevent nutrient deficiencies. In highly endemic areas, such as Zanzibar, treatment is not recommended in asymptomatic cases because of frequent reinfections. This is not unproblematic, however, since recent research have shown that giardiasis in childhood is associated with malnutrition, stunted growth and impaired cognitive development regardless of the presence of diarrhoea [56, 70, 71]. Blastocystis sp. on the other hand, is common in western high income countries (7-20\% prevalence) where other intestinal parasites are quite rare. Because of the uncertain pathogenicity, it is mainly treated in prolonged cases of gastrointestinal disturbances where other possible causes are ruled out. In our study Giardia was most prevalent among children two to five years of age, in agreement with several reports from developing countries [53, 56, 71]. An immunity response, which can be individually variable and influenced by nutritional status, genetic factors, and repeated exposure to Giardia, has been suggested to contribute to lower detection rates of Giardia seen in older children and also as an explanation to asymptomatic infections [67]. Although the examined population is too small to draw any 
firm conclusions, the different age distributions of Giardia and Blastocystis found in our study with increasing prevalence of Blastocystis with increasing age may indicate that the two parasites interact differently with the nonspecific and specific immune defence of the host. More extensive case-controlled studies of different Blastocystis subtypes in patients with gastrointestinal diseases, as well as longitudinal studies to determine the clinical impact of primary infections, are required to elucidate the role of Blastocystis in gastro-intestinal health and disease.

\section{Conclusions}

Carriage of intestinal parasites was very common in the studied population in Zanzibar. Compared to traditional detection with microscopy we found PCR-based methods to be vastly more sensitive and these should be used in further epidemiological studies. Blastocystis was the most common parasite, and subtype analysis revealed ST1-3 to be common. ST4, a subtype common in Europe, was completely absent in our study, further corroborating the geographical differences in subtype distributions previously reported. We found that Blastocystis and Giardia had different age distributions, possibly indicating differences in transmission routes, immunity, and/or other host factors impacting these two species in this region.

\section{Acknowledgments}

We would like to thank all the participants of the study, Omar Hamsa, head of the Jambiani health clinic at the time, for his great effort in sample collection, Titia Kortbeek and Jeroen Roelfsema for sharing their multiplex qPCR assay, and Agheleh Hossainy for performing parts of the laboratory work.

\section{Funding}

Grants for this study was given by Västerbotten County Council.

\section{Availability of data and materials}

The data supporting the conclusions of this article are included within the article.

\section{Authors' contributions}

JF conceived the study, analyzed the data, drafted and wrote the manuscript. MG conceived the study, performed microscopy, revised and wrote the manuscript. LS, HE and SK developed and performed PCR-based assays. BE conceived the study, collected data and revised the manuscript. All authors read and approved the final manuscript.

\section{Competing interests}

The authors declare that they have no competing interests.

\section{Consent for publication}

Not applicable.

\section{Ethics approval and consent to participate}

The study was approved by the regional ethical board at Umeå University, Sweden (Dnr 2012-406-31M).

\section{Author details}

'Division of Clinical Bacteriology, Department of Clinical Microbiology, Umeå University, SE-901 87 Umeå, Sweden. ²Division of Infectious Diseases, Department of Clinical Microbiology, Umeå University, SE-901 87 Umeå, Sweden.
Received: 25 January 2016 Accepted: 10 June 2016

Published online: 29 June 2016

\section{References}

1. Diamond LS, Clark CG. A redescription of Entamoeba histolytica Schaudinn, 1903 (Emended Walker, 1911) separating it from Entamoeba dispar Brumpt, 1925. J Eukaryot Microbiol. 1993:40:340-4.

2. Silberman JD, Sogin ML, Leipe DD, Clark CG. Human parasite finds taxonomic home. Nature. 1996:380:398.

3. Scanlan PD, Stensvold CR. Blastocystis: getting to grips with our guileful guest. Trends Parasitol. 2013;29:523-9.

4. Alfellani MA, Taner-Mulla D, Jacob AS, Imeede CA, Yoshikawa H, Stensvold CR, Clark CG. Genetic diversity of Blastocystis in livestock and zoo animals. Protist. 2013;164:497-509.

5. González-Moreno O, Domingo L, Teixidor J, Gracenea M. Prevalence and associated factors of intestinal parasitisation: a cross-sectional study among outpatients with gastrointestinal symptoms in Catalonia, Spain. Parasitol Res. 2011;108:87-93.

6. Rene BA, Stensvold CR, Badsberg JH, Nielsen HV. Subtype analysis of Blastocystis isolates from Blastocystis cyst excreting patients. Am J Trop Med Hyg. 2009;80:588-92.

7. Roberts T, Barratt J, Harkness J, Ellis J, Stark D. Comparison of microscopy, culture, and conventional polymerase chain reaction for detection of Blastocystis sp. in clinical stool samples. Am J Trop Med Hyg. 2011;84:308-12.

8. Li LH, Zhang XP, Lv S, Zhang L, Yoshikawa H, Wu Z, Steinmann P, Utzinger J, Tong XM, Chen SH, Zhou XN. Cross-sectional surveys and subtype classification of human Blastocystis isolates from four epidemiological settings in China. Parasitol Res. 2007;102:83-90.

9. El Safadi D, Gaayeb L, Meloni D, Cian A, Poirier P, Wawrzyniak I, Delbac F, Dabboussi F, Delhaes L, Seck M, Hamze M, Riveau G, Viscogliosi E. Children of Senegal River Basin show the highest prevalence of Blastocystis sp. ever observed worldwide. BMC Infect Dis. 2014:14:164.

10. Roberts T, Stark D, Harkness J, Ellis J. Update on the pathogenic potential and treatment options for Blastocystis sp. Gut Pathog. 2014;6:17.

11. Scanlan PD, Stensvold CR, Rajilić-Stojanović M, Heilig HG, De Vos WM, OToole PW, Cotter PD. The microbial eukaryote Blastocystis is a prevalent and diverse member of the healthy human gut microbiota. FEMS Microbiol Ecol. 2014:90:326-30

12. Stensvold CR, Suresh GK, Tan KS, Thompson RC, Traub RJ, Viscogliosi E, Yoshikawa H, Clark CG. Terminology for Blastocystis subtypes - a consensus. Trends Parasitol. 2007;23:2393-6.

13. Stensvold CR, Alfellani MA, Nørskov-Lauritsen S, Prip K, Victory EL, Maddox C, Nielsen HV, Clark CG. Subtype distribution of Blastocystis isolates from synanthropic and zoo animals and identification of a new subtype. Int J Parasitol. 2009:39:473-9.

14. Parkar U, Traub RJ, Kumar S, Mungthin M, Vitali S, Leelayoova S, Morris K, Thompson RC. Direct characterization of Blastocystis from faeces by PCR and evidence of zoonotic potential. Parasitol. 2007;134:359-67.

15. Fayer $R$, Santin M, Macarisin D. Detection of concurrent infection of dairy cattle with Blastocystis, Cryptosporidium, Giardia, and Enterocytozoon by molecular and microscopic methods. Parasitol Res. 2012:111:1349-55.

16. Alfellani MA, Stensvold CR, Vidal-Lapiedra A, Onuoha ES, Fagbenro-Beyioku AF, Clark CG. Variable geographic distribution of Blastocystis subtypes and its potential implications. Acta Trop. 2013;126:11-8.

17. Hussein EM, Hussein AM, Eida MM, Atwa MM. Pathophysiological variability of different genotypes of human Blastocystis hominis Egyptian isolates in experimentally infected rats. Parasitol Res. 2008;102:853-60.

18. Souppart L, Moussa H, Cian A, Sanciu G, Poirier P, El Alaoui H, Delbac F, Boorom K, Delhaes L, Dei-Cas E, Viscogliosi E. Subtype analysis of Blastocystis isolates from symptomatic patients in Egypt. Parasitol Res. 2010;106:505-11.

19. Fouad SA, Basyoni MM, Fahmy RA, Kobaisi MH. The pathogenic role of different Blastocystis hominis genotypes isolated from patients with irritable bowel syndrome. Arab J Gastroenterol. 2011;12:194-200.

20. El Deeb HK, Khodeer S. Blastocystis spp.: frequency and subtype distribution in iron deficiency anemic versus non-anemic subjects from Egypt. J Parasitol. 2013;99:599-602.

21. Abdulsalam AM, Ithoi I, Al-Mekhlafi HM, Al-Mekhlafi AM, Ahmed A, Surin J. Subtype distribution of Blastocystis isolates in Sebha, Libya. PLoS One. 2013:8:e84372.

22. Petrášová J, Uzlíková M, Kostka M, Petrželková KJ, Huffman MA, Modrý D. Diversity and host specificity of Blastocystis in syntopic primates on Rubondo Island, Tanzania. Int J Parasitol. 2011;41:1113-20. 
23. Forsell J, Koskiniemi S, Hedberg I, Edebro H, Evengård B, Granlund M. Evaluation of factors affecting real-time PCR performance for diagnosis of Entamoeba histolytica and Entamoeba dispar in clinical stool samples. J Med Microbiol. 2015:64:1053-62.

24. Allen AVH, Ridley DS. Further observations on the formol-ether concentration technique for faecal parasites. J Clin Pathol. 1970;23:545-6.

25. Verweij JJ, Oostvogel F, Brienen EA, Nang-Beifubah A, Ziem J, Polderman AM. Short communication: prevalence of Entamoeba histolytica and Entamoeba dispar in northern Ghana. Trop Med Int Health. 2003;8:1153-6.

26. Verweij JJ, Schinkel J, Laeijendecker D, van Rooyen MA, van Lieshout L, Polderman AM. Real-time PCR for the detection of Giardia lamblia. Mol Cell Probes. 2003;17:223-5.

27. Verweij JJ, Mulder B, Poell B, van Middelkoop D, Brienen EAT, van Lieshout L. Real-time PCR for the detection of Dientamoeba fragilis in fecal samples. Mol Cell Probes. 2007:21:400-4.

28. Fontaine M, Guillot E. Development of a TaqMan quantitative PCR assay specific for Cryptosporidium parvum. FEMS Microbiol Lett. 2002;214:13-7.

29. Scicluna SM, Tawari B, Clark CG. DNA barcoding of Blastocystis. Protist. 2006; $157: 77-85$

30. Stensvold CR, Ahmed UN, Andersen LO, Nielsen HV. Development and evaluation of a genus-specific, probe-based, internal-process-controlled realtime PCR assay for sensitive and specific detection of Blastocystis spp. J Clin Microbiol. 2012;50:1847-51.

31. Vanni I, Cacciò SM, van Lith L, Lebbad M, Svärd SG, Pozio E, Tosini F. Detection of Giardia duodenalis assemblages A and B in human feces by simple, assemblage-specific PCR assays. PLoS Negl Trop Dis. 2012;6:e1776.

32. Stark D, Al-Qassab SE, Barratt JL, Stanley K, Roberts T, Marriott D, Harkness J, Ellis JT. Evaluation of multiplex tandem real-time PCR for detection of Cryptosporidium spp., Dientamoeba fragilis, Entamoeba histolytica, and Giardia intestinalis in clinical stool samples. J Clin Microbiol. 2011:49:257-62.

33. van Coppenraet LE B, Wallinga JA, Ruijs GJ, Bruins MJ, Verweij JJ. Parasitological diagnosis combining an internally controlled real-time PCR assay for the detection of four protozoa in stool samples with a testing algorithm for microscopy. Clin Microbiol Infect. 2009;15:869-74.

34. Verweij JJ. Application of PCR-based methods for diagnosis of intestinal parasitic infections in the clinical laboratory. Parasitol. 2014;141:1863-72.

35. Cartwright CP. Utility of multiple-stool specimen ova and parasite examinations in a high prevalence setting. J Clin Microbiol. 1999;6:2408-11.

36. Marti $\mathrm{H}$, Koella JC. Multiple stool examinations for ova and parasites and rate of false-negative results. J Clin Microbiol. 1993;6:3044-5.

37. Elfving K, Andersson M, Msellem MI, Welinder-Olsson C, Petzold M, Björkman A, Trollfors B, Mårtensson A, Lindh M. Real-time PCR threshold cycle cutoffs help to identify agents causing acute childhood diarrhea in Zanzibar. J Clin Microbiol. 2014;52:916-23.

38. Albonico M, Chwaya HM, Montresor A, Stolfzfus RJ, Tielsch JM, Alawi KS, Savioli L. Parasitic infections in Pemba Island school children. East Afr Med J. 1997:74:294-8

39. Renganathan E, Ercole E, Albonico M, De Gregorio G, Alawi KS, Kisumku UM, Savioli L. Evolution of operational research studies and development of a national control strategy against intestinal helminths in Pemba Island, 198892. Bull World Health Organ. 1995;73:183-90.

40. Poirier P, Wawrzyniak I, Albert A, El Alaoui H, Delbac F, Livrelli V. Development and evaluation of a real-time PCR assay for detection and quantification of Blastocystis parasites in human stool samples: prospective study of patients with hematological malignancies. J Clin Microbiol. 2011;49:975-83.

41. Abdulsalam AM Ithoi I, Al-Mekhlafi HM, Khan AH, Ahmed A, Surin J, Mak JW. Prevalence, predictors and clinical significance of Blastocystis sp. in Sebha, Libya. Parasit Vectors. 2013;6:86

42. Cabrine-Santos M, Cintra Edo N, do Carmo RA, Nascentes GA, Pedrosa AL, Correia D, de Oliveira-Silva MB. Occurrence of Blastocystis spp. in Uberaba, Minas Gerais, Brazil. Rev Inst Med Trop Sao Paulo. 2015;57:211-4.

43. Nimri L, Batchoun R. Intestinal colonization of symptomatic and asymptomatic schoolchildren with Blastocystis hominis. J Clin Microbiol. 1994:32:2865-6.

44. Scanlan PD, Stensvold CR, Cotter PD. Development and application of a Blastocystis subtype-specific PCR assay reveals that mixed-subtype infections are common in a healthy human population. Appl Environ Microbiol. 2015; 81:4071-6.

45. Thathaisong U, Siripattanapipong S, Mungthin M, Pipatsatitpong D, Tan-ariya P, Naaglor T, Leelayoova S. Identification of Blastocystis subtype 1 variants in the Home for Girls, Bangkok, Thailand. Am J Trop Med Hyg. 2013;88:352-8.
46. Leelayoova S, Siripattanapipong S, Thathaisong U, Naaglor T, Taamasri $P$, Piyaraj P, Mungthin M. Drinking water: a possible source of Blastocystis spp. subtype 1 infection in schoolchildren of a rural community in central Thailand. Am J Trop Med Hyg. 2008:79:401-6.

47. Malheiros AF, Stensvold CR, Clark CG, Braga GB, Shaw JJ. Short report: Molecular characterization of Blastocystis obtained from members of the indigenous Tapirapé ethnic group from the Brazilian Amazon region, Brazil. Am J Trop Med Hyg. 2011;85:1050-3.

48. Forsell J, Granlund M, Stensvold CR, Clark CG, Evengård B. Subtype analysis of Blastocystis isolates in Swedish patients. Eur J Clin Microbiol Infect Dis. 2013:31:1689-96.

49. Lane S, Lloyd D. Current trends in research into the waterborne parasite Giardia. Crit Rev Microbiol. 2002;28:123-47.

50. Savioli L, Smith H, Thompson A. Giardia and Cryptosporidium join the 'Neglected Diseases Initiative'. Trends Parasitol. 2006;22:203-8.

51. Siwila J, Phiri IG, Enemark HL, Nchito M, Olsen A. Intestinal helminths and protozoa in children in pre-schools in Kafue district, Zambia. Trans R Soc Trop Med Hyg. 2010;104:122-8.

52. Guimarães S, Sogayar Ml. Occurrence of Giardia lamblia in children of municipal day-care centers from Botucatu, São Paulo State, Brazil. Rev Inst Med Trop Sao Paulo. 1995:37:501-6.

53. Ankarklev J, Hestvik E, Lebbad M, Lindh J, Kaddu-Mulindwa DH, Andersson JO, Tylleskär T, Tumwine JK, Svärd SG. Common coinfections of Giardia intestinalis and Helicobacter pylori in non-symptomatic Ugandan children. PLoS Negl Trop Dis. 2012;6:e1780.

54. Lebbad M, Mattsson JG, Christensson B, Ljungström B, Backhans A, Andersson JO, Svärd SG. From mouse to moose: multilocus genotyping of Giardia isolates from various animal species. Vet Parasitol. 2010;168:231-9.

55. Franzén O, Jerlström-Hultqvist J, Castro E, Sherwood E, Ankarklev J, Reiner DS, Palm D, Andersson JO, Andersson B, Svärd SG. Draft genome sequencing of Giardia intestinalis assemblage B isolate GS: is human giardiasis caused by two different species? PLoS Pathog. 2009;5:e1000560.

56. Ignatius R, Gahutu JB, Klotz C, Steininger C, Shyirambere C, Lyng M, Musemakweri A, Aebischer T, Martus P, Harms G, Mockenhaupt FP. High prevalence of Giardia duodenalis Assemblage B infection and association with underweight in Rwandan children. PLoS Negl Trop Dis. 2012;6:e1677.

57. Di Cristanziano V, Santoro M, Parisi F, Albonico M, Shaali MA, Di Cave D, Berrilli F. Genetic characterization of Giardia duodenalis by sequence analysis in humans and animals in Pemba Island, Tanzania. Parasitol Int. 2014;63:438-41.

58. Ferreira FS, Centeno-Lima S, Gomes J, Rosa F, Rosado V, Parreira R, Cravo L, Atouguia J, Távora TL. Molecular characterization of Giardia duodenalis in children from the Cufada Lagoon Natural Park, Guinea-Bissau. Parasitol Res. 2012:111:2173-7.

59. El Fatni C, Olmo F, El Fatni H, Romero D, Rosales MJ. First genotyping of Giardia duodenalis and prevalence of enteroparasites in children from Tetouan (Morocco). Parasite. 2014;21:48.

60. Lalle M, Bruschi F, Castagna B, Campa M, Pozio E, Cacciò SM. High genetic polymorphism among Giardia duodenalis isolates from Sahrawi children. Trans R Soc Trop Med Hyg. 2009;103:834-8.

61. Berrilli F, D'Alfonso R, Giangaspero A, Marangi M, Brandonisio O, Kaboré Y, Glé C, Cianfanelli C, Lauro R, Di Cave D. Giardia duodenalis genotypes and Cryptosporidium species in humans and domestic animals in Côte d'Ivoire: occurrence and evidence for environmental contamination. Trans R Soc Trop Med Hyg. 2012;106:191-5.

62. Fahmy HM, El-Serougi AO, El Deeb HK, Hussein HM, Abou-Seri HM, Klotz C, Aebischer T, El Sayed Khalifa Mohamed K. Giardia duodenalis assemblages in Egyptian children with diarrhea. Eur J Clin Microbiol Infect Dis. 2015;34:1573-81.

63. Amer SE. Genotypic and phylogenetic characterization of Giardia intestinalis from human and dairy cattle in Kafr El Sheikh Governorate, Egypt. J Egypt Soc Parasitol. 2015;43:133-46.

64. Foronda P, Bargues MD, Abreu-Acosta N, Periago MV, Valero MA, Valladares B, Mas-Coma S. Identification of genotypes of Giardia intestinalis of human isolates in Egypt. Parasitol Res. 2008;103:1177-81.

65. El-Shazly AM, Mowafy N, Soliman M, El-Bendary M, Morsy AT, Ramadan NI, Arafa WA. Egyptian genotyping of Giardia lamblia. J Egypt Soc Parasitol. 2004:34:265-80.

66. Gelanew T, Lalle M, Hailu A, Pozio E, Cacciò SM. Molecular characterization of human isolates of Giardia duodenalis from Ethiopia. Acta Trop. 2007;102:92-9.

67. Bartelt LA, Sartor RB. Advances in understanding Giardia: determinants and mechanisms of chronic sequelae. F1000Prime Rep. 2015;7:62. 
68. Gascón J, Vargas M, Schellenberg D, Urassa H, Casals C, Kahigwa E, Aponte $\mathrm{JJ}$, Mshinda $\mathrm{H}$, Vila J. Diarrhoea in children under 5 years of age from Ifakara, Tanzania: a case-control study. J Clin Microbiol. 2001;38:4459-62.

69. Platts-Mills JA, Gratz J, Mduma E, Svensen E, Amour C, Liu J, Maro A, Saidi Q Swai N, Kumburu H, McCormick BJ, Kibiki G, Houpt ER. Association between stool enteropathogen quantity and disease in Tanzanian children using TaqMan array cards: a nested case-control study. Am J Trop Med Hyg. 2014; 90:133-8.

70. Berkman DS, Lescano AG, Gilman RH, Lopez SL, Black MM. Effects of stunting, diarrhoeal disease, and parasitic infection during infancy on cognition in late childhood: a follow-up study. Lancet. 2002;359:564-71.

71. Heimer J, Staudacher O, Steiner F, Kayonga Y, Havugimana JM, Musemakweri A, Harms G, Gahutu JB, Mockenhaupt FP. Age-dependent decline and association with stunting of Giardia duodenalis infection among schoolchildren in rural Huye district, Rwanda. Acta Trop. 2015;145:17-22.

\section{Submit your next manuscript to BioMed Central} and we will help you at every step:

- We accept pre-submission inquiries

- Our selector tool helps you to find the most relevant journal

- We provide round the clock customer support

- Convenient online submission

- Thorough peer review

- Inclusion in PubMed and all major indexing services

- Maximum visibility for your research

Submit your manuscript at www.biomedcentral.com/submit 